\title{
Surgery for bicuspid valve aortopathy clarified-for now
}

\author{
John S. Ikonomidis, MD, PhD
}

\author{
From the Division of Cardiothoracic Surgery, Medical University of South Carolina, Charleston, SC. \\ Disclosures: Author has nothing to disclose with regard to commercial support. \\ Available ahead of print Jan 24, 2016. \\ Address for reprints: John S. Ikonomidis, MD, PhD, Division of Cardiothoracic Surgery, Suite 7030, 25 Courtenay \\ Dr, Charleston, SC 29425 (E-mail: ikonomij@musc.edu). \\ J Thorac Cardiovasc Surg 2016;151:967-8 \\ $0022-5223 / \$ 36.00$ \\ Copyright (c) 2016 by The American Association for Thoracic Surgery \\ http://dx.doi.org/10.1016/j.jtcvs.2016.01.010
}

In 2010, a joint guideline document was published ${ }^{1}$ for the diagnosis and management of patients with thoracic aortic disease. In this document, patients with bicuspid aortic valve-related aortopathy are discussed and recommendations are made. A Class I recommendation (Level of Evidence C) from this article was that asymptomatic patients with bicuspid aortic valve disease-related ascending aortopathy should undergo elective operation at diameters between 4 and $5 \mathrm{~cm}$ depending on the clinical condition. A Class IIa indication (Level of Evidence C) was defined in which asymptomatic patients with bicuspid aortic valve-related aortopathy who have a cross-sectional aortic area (centimeters squared) calculation indexed for height (meters) of greater than 10 also should be considered for operation.

In contrast to this, a second guideline document was published $^{2}$ in which listed as a Class I indication (Level of Evidence B) for surgery in bicuspid aortic valve-related aortopathy was elective operation for patients with an aortic diameter greater than $5.5 \mathrm{~cm}$. Two Class IIa indications (Level of Evidence C) also were included. The first recommended elective surgery for an ascending aortic diameter greater than $5 \mathrm{~cm}$ plus 1 risk factor (a family history of aortic dissection or rate of increase in diameter $\geq 0.5 \mathrm{~cm}$ per year). The second Class IIa indication recommended that the ascending aorta could be replaced at the time of surgery for bicuspid aortic valve-related aortopathy for diameters greater than $4.5 \mathrm{~cm}$.

In the wake of these conflicting recommendations, a statement of clarification has been generated as a result of a meeting of the subcommittee representing members of the 2 writing committees for the guideline statements discussed earlier. At this meeting, the evidence was reviewed, consensus was reached, and an addendum was crafted ${ }^{3}$ to address both of the guidelines. This was thought to be necessary because of the current paucity of data defining the ascending aortic diameter in which the risk of dissection was high enough to warrant operative intervention in patients who do not otherwise fulfill criteria for aortic valve replacement in patients with congenitally bicuspid aortic valves.

As a result of these deliberations, the recommendations were modified to a Class I recommendation (Level of

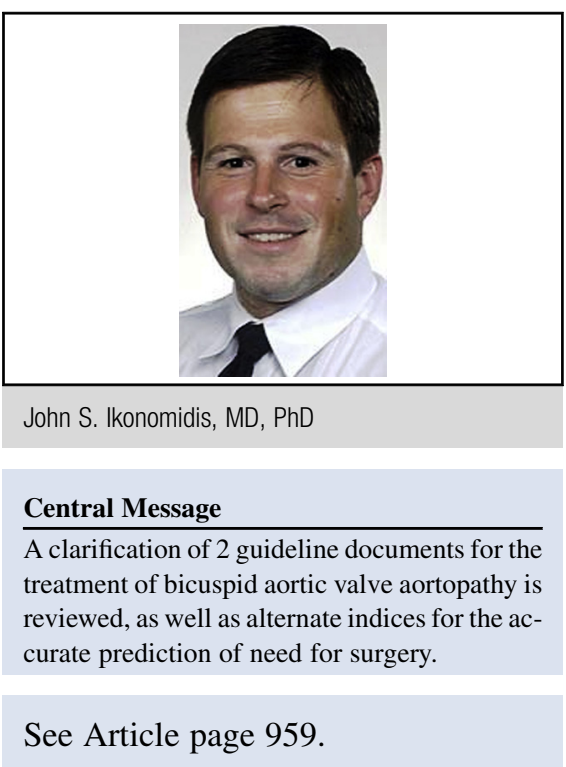

Evidence B) that operative intervention to replace the aortic root or the ascending aorta is indicated in asymptomatic patients with bicuspid aortic valve if the diameter of the aortic root or ascending aorta is $5.5 \mathrm{~cm}$ or greater. Further, a Class IIa (Level of Evidence B) was offered that operative intervention to repair or replace the aortic root to replace the ascending aorta is reasonable in asymptomatic patients with bicuspid aortic valve if the diameter of the aortic root or ascending aorta is $5 \mathrm{~cm}$ or greater and an additional risk factor for dissection is present (consisting of a family history of aortic dissection and an aortic growth rate $>0.5 \mathrm{~cm}$ per year) or if the patient is at low surgical risk and the surgery is performed by an experienced aortic surgical team with established expertise in these procedures. Last, a Class IIa recommendation (Level of Evidence C) was given that replacement of the ascending aorta is reasonable in patients with bicuspid aortic valve undergoing aortic valve replacement because of severe aortic stenosis or aortic regurgitation when the diameter of the ascending aorta is greater than $4.5 \mathrm{~cm}$.

These recommendations are reasonable. There are surprisingly little data in the current literature that definitively track the incidence of dissection or other aortic-related complications in patients with bicuspid valve aortopathy. The reason for this is intuitively obvious, because it would be very difficult to conduct natural history studies on the appropriate patient population when a safe surgical solution exists as definitive therapy. As such, definitive surgical recommendations based on aortic diameter may never come to light. 
An important consideration related to the guidelines listed is the limited nature of the indices used to predict need for operation. One previous guideline discussed aortic root cross-sectional area-to-height ratio as a predictor of aortic dissection, ${ }^{1}$ but this was not incorporated into the current clarification statement. In addition, natural history studies have stratified patients with thoracic aortic aneurysms related to surface area of the patient, ${ }^{4}$ but this has not been applied specifically to bicuspid aortic valverelated aortopathy. Biochemical predictors have not made their way into the mainstream with regard to the possibility of predicting when patients should undergo surgery. For example, our group has shown that a multi-analyte assessment of matrix metalloproteinases and their endogenous inhibitors in addition to specific micro-RNAs active in the cardiovascular system can predict with a high degree of certainty the presence of a bicuspid aortic valve-related aneurysm and that these indices change directly in proportion to the size of the aneurysm. ${ }^{5}$ Further studies from our group and others have shown that valve cusp configuration can predict the aggressiveness of ascending aortic remodeling, with the left-right cusp configuration associated with the most histologic ${ }^{6}$ and biochemical $^{7}$ derangements for similar aneurysm sizes. Thus, during surgery aortic valve replacement, on encountering a Sievers I bicuspid aortic valve with left-right cusp fusion and a marginal ascending aortic size, the surgeon may be justified in pursuing aortic replacement if there is concern regarding the integrity of the aortic wall. With improved resolution of magnetic resonance imaging and computed tomography scans, it is becoming possible to accurately measure aortic wall thickness, which would allow surface tension measurements and the generation of a 3-dimensional wall tension map on the aorta, with surgery recommended when wall tension exceeds a critical value. ${ }^{8}$
Further studies are necessary and ongoing to further define the utility of the described adjunct measurements to aortic size as predictors for operation, and perhaps make more stationary the moving target of correct indications for repair of ascending aortopathy related to congenitally bicuspid aortic valves.

\section{References}

1. Hiratzka LF, Bakris GL, Beckman JA, Bersin RM, Carr VF, Casey DE Jr, et al. 2010 ACCF/AHA/AATS/ACR/ASA/SCA/SCAI/SIR/STS/SVM guidelines for the diagnosis and management of patients with thoracic aortic disease: a report of the American College of Cardiology Foundation/American Heart Association Task Force on Practice Guidelines, American Association for Thoracic Surgery, American College of Radiology, American Stroke Association, Society of Cardiovascular Anesthesiologists, Society for Cardiovascular Angiography and Interventions, Society of Interventional Radiology, Society of Thoracic Surgeons, and Society for Vascular Medicine [published correction appears in Circulation. 2010;122:e410]. Circulation. 2010;121:e266-369.

2. Nishimura RA, Otto CM, Bonow RO, Carabello BA, Erwin JP III, Guyton RA, et al. 2014 AHA/ACC guideline for the management of patients with valvular heart disease: a report of the American College of Cardiology/American Heart Association Task Force on Practice Guidelines [published corrections appear in Circulation. 2014;129:e651 and Circulation. 2014;130:e120]. Circulation. 2014; 129:e521-643.

3. Hiratzka LF, Nishimura RA, Bonow RO, Creager MA, Guyton RA, Isselbacher EM, et al. Surgery for aortic dilatation in patients with bicuspid aortic valves: a statement of clarification from the American College of Cardiology/ American Heart Association Task Force on Clinical Practice Guidelines. J Am Coll Cardiol. 2016;67:724-31.

4. Davies RR, Gallo A, Coady MA, Tellides G, Botta DM, Burke B, et al. Novel measurement of relative aortic size predicts rupture of thoracic aortic aneurysms. Ann Thorac Surg. 2006;81:169-77.

5. Ikonomidis JS, Ruddy JM, Benton SM Jr, Arroyo J, Brinsa TA, Stroud RE, et al. Aortic dilatation with bicuspid aortic valves: cusp fusion correlates to matrix metalloproteinases and inhibitors. Ann Thorac Surg. 2012;93:457-63.

6. Russo CF, Cannata A, Lanfranconi M, Vitali E, Garatti A, Bonacina E. Is aortic wall degeneration related to bicuspid aortic valve anatomy in patients with valvular disease? J Thorac Cardiovasc Surg. 2008;136:937-42.

7. Ikonomidis JS, Ivey CR, Wheeler JB, Akerman AW, Rice A, Patel RK, et al. Plasma biomarkers for distinguishing etiological subtypes of thoracic aortic aneurysm disease. J Thorac Cardiovasc Surg. 2013;145:1326-33.

8. Nathan DP, Xu C, Plappert T, Desjardins B, Gorman JH III, Bavaria JE, et al. Increased ascending aortic wall stress in patients with bicuspid aortic valves. Ann Thorac Surg. 2011;92:1384-9. 